\title{
RESPON GURU DAN PESERTA DIDIK TERHADAP PEMBELAJARAN FISIKA DENGAN MODEL INKUIRI TERBIMBING DIPADU ADVANCE ORGANIZER
}

\author{
Mahesti Kusdiastuti $^{*}$, Ahmad Harjono², Gunawan², Mir'atun Nisyah' ${ }^{1}$ \\ ${ }^{1}$ Program Studi Magister Pendidikan IPA, Universitas Mataram \\ ${ }^{2}$ Program Studi Pendidikan Fisika, Universitas Mataram \\ *Email: mahestikusdiastuti25@gmail.com
}

DOI: http://dx.doi.org/10.29303/jpft.v5i1.1174

\begin{abstract}
This study aims to determine the response of teachers and students to physics learning with a guided inquiry learning model combined with an advanced organizer. This research was conducted in three senior high schools in Mataram. This research is a pre-experimental study. The subjects of this study were 3 physics teachers and 60 students in Mataram. The data obtained in this study are teacher and student' questionnaire response data. The results of the study showed that both the response of students and the response to learning with guided inquiry learning models combined with advanced organizers included in the excellent category.
\end{abstract}

Keywords: Advance Organizer, Guided Inquiry, Teacher, Student Responses

\section{PENDAHULUAN}

Fisika adalah salah satu mata pelajaran yang prosesnya menggunakan metode ilmiah. Artinya dalam proses pembelajaran fisika tidak hanya tentang penguasaan pengetahuan dalam bentuk fakta, konsep, atau prinsip, tetapi juga pengalaman dalam proses penemuan menggunakan keterampilan proses ilmiah serta keterampilan berpikir (Gunawan, 2015; Usmedi et al. 2017).

Pembelajaran fisika tidak terlepas dari pendekatan ilmiah. Hal ini menyebabkan diperlukan suatu model pembelajaran yang mendukung peserta didik untuk menerapkan pengetahuan yang dimiliki, memahami dan melakukan penyelidikan berdasarkan situasi nyata serta masih dibawah arahan/bimbingan guru.

Namun, kenyataan dilapangan pembelajaran fisika dalam prosesnya cendrung bersifat satu arah. Artinya, guru aktif menyampaikan materi dan peserta didik hanya mendengarkan penyampaian materi dari guru. Selain itu, pembelajaran fisika berorientasi pada penghafalan rumus dan perhitungan secara matematis. Padahal pembelajaran fisika sebaiknya dilaksanakan tidak terlepas dari kegiatan penyelidikan yang mampu mengembangkan kemampuan berpikir peserta didik.

Salah satu model pembelajaran yang berorientasi penyelidikan yaitu model pembelajaran inkuiri. Model pembelajaran inkuri merupakan model pembelajaran berbasis peyelidikan dimana peserta didik mencari sendiri jawaban dari permasalahan yang dihadapi (Sanjaya, 2011; Kusdiastuti et al. 2016). Model pembelajaran inkuiri memiliki berbagai jenis yaitu model pembelajaran inkuri terbuka, terbimbing dan terpimpin. Model pembelajaran inkuri terbimbing sangat cocok digunakan pada peserta didik yang belum pernah mengalami pembelajaran yang berbasis penyelidikan, sehingga sangat dibutuhkan bimbingan atau arahan guru dalam melakukan percobaan atau penyelidikan.

Model pembelajaran inkuiri terbimbing merupakan model pembelajaran yang melibatkan peserta didik secara aktif mulai dari merumuskan masalah hingga menarik kesimpulan (Nurmayani et al. 2018). Model pembelajaran inkuiri terbimbing memiliki beberapa keunggulan yaitu membangun kemampuan berpikir peserta didik dan mendorong keterlibatan 
aktif peserta didik dalam menyelesaikan masalah (Yeritia et al. 2017).

Selain memiliki keunggulan, model pembelajaran inkuri terbimbing juga memiliki kekurangan. Model pembelajaran inkuiri terbimbing menuntut kesiapan yang matang baik dari guru maupun peserta didik agar dapat berjalan sesuai dengan tahapan pembelajaran. Kesiapan dalam pembelajaran inkuri terbimbing yaitu peserta didik harus mempunyai pengetahuan awal yang memadai dalam proses pembelajaran karena dalam tahapan pembelajaran inkuri terbimbing, peserta didik dituntut merumuskan masalah secara mandiri. Tanpa adanya pengetahuan awal yang memadai maka pembelajaran inkuiri terbimbing tidak dapat berjalan sesuai tahapan. Untuk mengatasi kekurangan tersebut, model pembelajaran inkuiri dapat dipadukan dengan model pembelajaran yang mampu menstimulus pengetahuan awal peserta didik. Salah satu model pembelajaran tersebut adalah model pembelajaran advance organizer.

Model advance organizer merupakan strategi pembelajaran yang memudahkan dalam menghubungkan pengetahuan baru dengan pengetahuan awal yang ada pada struktur kognitif peserta didik (Tasiwan et al. 2014). Sama halnya dengan model pembelajaran lainnya, model advance organizer mempunyai 3 tahap yaitu 1) presentasi advance organizer, 2) presentasi tugas atau materi pembelajaran dan 3) penguatan struktur kognitif (Joyce et al. 2011).

Perpaduan model pembelajaran inkuiri terbimbing dan advance organizer menghasilkan 8 tahapan pembelajaran yaitu dimulai dari 1) presentasi advance organizer, 2) menyajikan pertanyaan atau masalah, 3) membuat hipotesis, 4) merancang percobaan, 5) melakukan percobaan, 6) mengumpulkan dan menganalisis data, 7) penguatan organisasi struktur kognitif dan 8) membuat kesimpulan.

Pembelajaran fisika dengan model inkuiri terbimbing dipadu advance organizer dimulai dengan presentasi advance organizer yang berupa peta konsep dan video yang berdurasi kurang dari 2 menit. Kemudian, dilanjutkan dengan menyajikan masalah atau pertanyaan yang diajukan oleh guru kemudian peserta didik membuat hipotesis dan melakukan percobaan hingga menganalisis data. Sebelum tahap terakhir membuat kesimpulan, ada tahapan penguatan organisasi struktur kognitif, pada tahap ini terjadi penggabungan pengetahuan baru dengan pengetahuan awal yang telah ada didalam struktur kognitif peserta didik. Hal ini dapat dilakukan dengan guru mengajukan beberapa pertanyaan.

Penelitian ini terfokus pada respon guru dan peserta didik terhadap perangkat dan proses pembelajaran model inkuiri terbimbing dipadu advance organizer yang diterapkan dalam pembelajaran fisika materi gerak harmonik sederhana.

\section{METODE PENELITIAN}

Penelitian dan pengembangan ini menggunakan model 4D (define, design, develop, dan dessiminate). Uji coba menggunakan jenis pre eksperimen. Penelitian ini dilakukan di tiga sekolah menengah atas di Kota Mataram dengan subjek penelitian sebanyak 3 guru mata pelajaran fisika dan 60 peserta didik kelas $\mathrm{X}$ MIA Tahun Ajaran 2018/2019. Data yang diperoleh dalam penelitian ini merupakan data respon peserta didik dan respon guru terhadap pembelajaran fisika dengan menggunakan model inkuiri terbimbing dipadu advance organizer. Data respon peserta didik dan guru diperoleh melalui angket yang menggunakan skala likert. Data yang telah diperoleh kemudian dianalisis secara deskriptif kuantitatif. 
HASIL DAN PEMBAHASAN

Data yang diperoleh adalah respon peserta didik dan guru terhadap pembelajaran fisika dengan menggunakan model inkuiri terbimbing dipadu advance organizer. Angket disusun berdasarkan aspek yang berkaitan dengan pembelajaran. Angket respon guru menilai beberapa aspek seperti tampilan, bahasa, kesesuain materi dan kejelasan materi dari RPP, LKPD, graphic dan video organizer serta materi ajar yang telah dikembangkan.

Hasil penelitian menunjukkan bahwa respon guru secara keseluruhan $87 \%$ memberikan respon positif terhadap pembelajaran fisika dengan model inkuiri terbimbing dipadu advance organizer. Respon guru dari berbagai aspek mulai dari tampilan dan pengunaan bahasa baik itu RPP, LKPD, graphic dan video organizer serta materi ajar, kemudian Kejelasan materi yang terdapat pada materi ajar, kejelasan indikator dan tujuan pembelajaran yang dirumuskan serta kejelasan petunjuk dan langkah kerja yang ada pada LKPD. Kemudian, aspek kesesuaian baik dari kesesuaian indikator pembelajaran dengan kompetensi dasar, tahapan pembelajaran dengan alokasi waktu dan kesesuaian tahapan pembelajaran yang ada di RPP dengan kegiatan yang ada di LKPD.

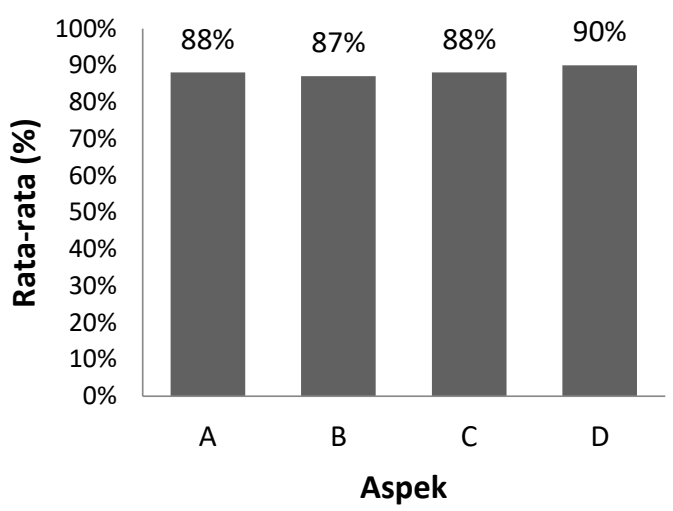

Gambar 1. Persentase Rata-Rata Respon Guru dari beberapa Aspek.

Hasil penelitian menunjukkan bahwa persentase rata-rata respon guru dari berbagai aspek disajikan pada Gambar 1 . Gambar 1 menunjukkan bahwa semua aspek diperoleh rata-rata diatas $80 \%$. Artinya perangkat pembelajaran yang dikembangkan mendapat respon postif dari guru. Adapun saran dari guru yaitu mengatur waktu dengan lebih baik lagi agar setiap tahapan dapat berjalan sesuai dengan rencana pembelajaran.

Selain diperoleh rata-rata respon guru dari beberapa aspek. Peneliti juga menganalisis rata-rata persentase respon guru dari perangkat yang dikembangkan mulai dari RPP, LKPD, Graphic \& Video Organizer serta Materi ajar disajikan pada Gambar 2.

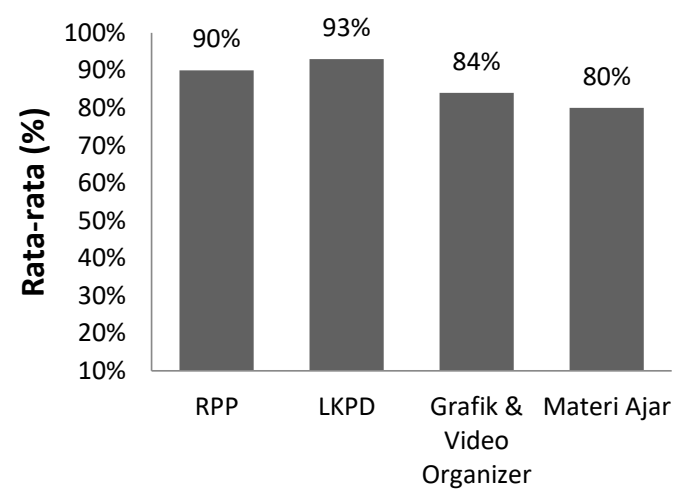

Gambar 2. Persentase Rata-Rata Respon Guru terhadap perangkat yang dikembangkan.

Gambar 2 menunjukkan bahwa respon guru terhadap perangkat yang dikembangkan secara keseluruhan mencapai $80 \%$. RPP yang dikembangkan sesuai dengan tahapan model pembelajaran inkuiri terbimbing dipadu advance organizer. Respon tertinggi ditunjukkan pada LKPD, LKPD yang disajikan memiliki tampilan yang mudah dimengerti, pengunaan bahasa yang tepat, kejelasan langkah-langkah kerja serta dalam LKPD memfasilitasi peserta didik dalam mengembangkan kemampuan berpikir.

Graphic dan video organizer yang dikembangankan ditampilkan setiap pertemuan pada awal pembelajaran. Graphic organizer berupa peta konsep dibagikan 
kepada masing-masing peserta didik, kemudian peserta didik ditampilkan video yang berdurasi kurang dari 2 menit. Materi ajar yang dikembangkan merupakan materi gerak harmonik sederhana. Materi ajar tersebut terdiri dari uraian materi, penjabaran persamaan-persamaan yang berkaitan dengan materi gerak harmonik sederhana dan sedikit contoh soal. Hal ini yang menjadi masukan dari guru agar contoh soal pada materi ajar agar ditambah. Artinya pada setiap sub materi terdapat contoh soal. Selain itu, materi ajar juga menampilkan manfaat-manfaat dalam kehidupan seharihari yang menggunakan prinsip gerak harmonik sederhana, hal ini sangat penting agar peserta didik untuk menarik perhatian peserta didik dengan mengaitkan pembelajaran fisika dengan kehidupan sehari-hari.

Selain respon guru, peneliti juga menganalisis respon peserta didik terhadap pembelajaran model inkuri terbimbing dipadu advance organizer. Angket respon peserta didik menilai 4 aspek yaitu motivasi, keaktifan, kerjasama dan sikap terhadap pembelajaran. Hasil penelitian menunjukkan bahwa respon peserta didik secara keseluruhan memberikan respon positif sebesar $92 \%$ dan termasuk dalam kategori sangat baik.

Selain diperoleh rata-rata persentase respon peserta didik secara keseluruhan. Peneliti juga menganalisis rata-rata persentase respon peserta didik pada setiap aspek. Hal ini ditunjukkan pada Gambar 3.

Gambar 3 menunjukkan bahwa ratarata persentase respon peserta didik pada setiap aspek yaitu diperoleh diatas $85 \%$ dan termasuk dalam kategori sangat baik. Pada aspek motivasi, peserta didik merasa termotivasi belajar fisika khusus pada materi gerak harmonik sederhana karena model pembelajaran yang sangat baru bagi peserta didik.

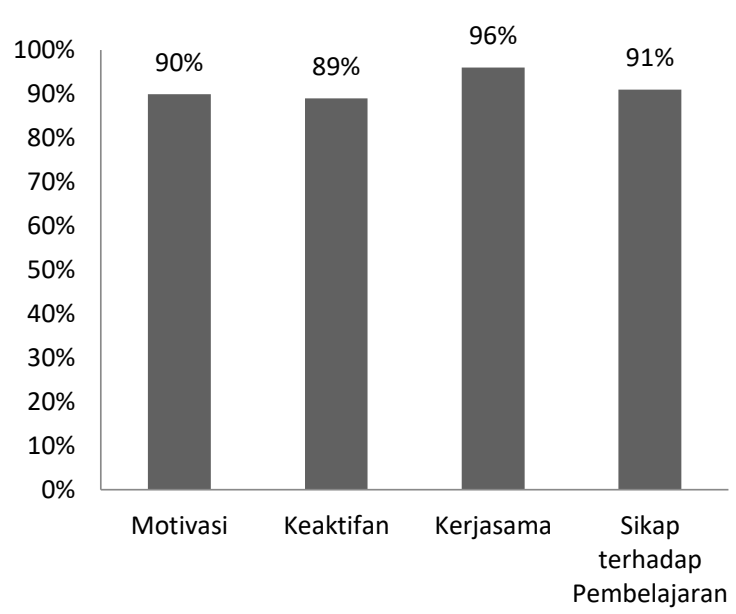

Gambar 3. Persentase Rata-Rata Respon Peserta Didik dari setiap Aspek.

Tahap awal pembelajaran guru menampilkan video organizer yang mampu menarik perhatian peserta didik. Penggunaan media komputer dalam proses pembelajaran mampu meningkatkan penguasaan konsep peserta didik (Dewi et al. 2016; Kusdiastuti et al. 2016).

Tahap selanjutnya adalah tahap melakukan percobaan untuk menyelesaikan masalah yang memotivasi peserta didik menyelesaikan masalah melalui penyeledikan. Hal ini sejalan dengan penelitian Kigo et al. (2018) menyatakan bahwa pembelajaran dengan advance organizer mampu meningkatkan motivasi peserta didik. Selanjutnya, Baity \& Jatmiko (2018) menyatakan bahwa pembelajaran dengan model inkuiri terbimbing mendapat respon positif dari peserta didik dalam menarik perhatian selama proses pembelajaran.

Aspek keaktifan dari Gambar 3 menunjukkan bahwa diperoleh $89 \%$ respon positif dari peserta didik. Proses pembelajaran dengan model inkuiri terbimbing dipadu advance organizer setiap pertemuan terdapat percobaan yang harus dilakukan secara berkelompok yang bertujuan untuk membangun keterampilan komunikasi melalui diskusi. Selain itu, diakhir percobaan selalu ada tahapan presentasi hasil dari percobaan yang telah 
dilakukan peserta didik. Pada tahapan presentasi, peserta didik diberikan kesempatan untuk memberikan tanggapan dan pertanyaan kepada kelompok yang presentasi. Hal inilah yang menyebabkan peserta didik menjadi lebih aktif dalam pembelajaran. Hal ini sejalan dengan Ambarsari et al. (2013) menyatakan bahwa peserta didik yang diajarakan dengan model pembelajaran inkuiri terbimbing menjadi lebih aktif selama proses pembelajaran.

Aspek kerjasama diperoleh 96\% respon peserta didik dan termasuk kategori sangat baik. Pembelajaran dengan model inkuiri terbimbing dipadu advance organizer mampu meningkatkan sikap kerjasama peserta didik. Hal ini dikarenakan, setiap percobaan dilakukan per kelompok, dimana satu kelompok terdiri dari 4-5 peserta didik. Selama proses percobaan, peserta didik saling membantu apabila ada temannya yang belum mengerti dalam menggunakan alat percobaan. Selain itu, didalam LKPD terdapat beberapa masalah yang harus diselesaikan dengan teman kelompoknya. Sehingga apabila ada teman yang kurang pahami, teman lainnya dapat membantu.

Aspek sikap terhadap pembelajaran diperoleh 91\% respon peserta didik. Sikap terhadap pembelajaran yang dimaksud meliputi peserta didik merasa pembelajaran dengan model inkuiri terbimbing dipadu advance organizer sangat berbeda dengan model pembelajaran yang telah diterapkan sebelumnya. Peserta didik merasa mudah memahami pelajaran fisika dengan diterapkan model inkuiri terbimbing dipadu advance organizer. Proses pembelajaran peserta didik merasa waktu berjalan cepat, artinya pembelajaran dengan model inkuiri terbimbing dipadu advance organizer tidak membosankan bagi peserta didik karena selama pembelajaran banyak hal yang dapat dilakukan seperti menonton video organizer, melakukan percobaan dan menyelesaikan masalah yang terdapat pada LKPD. Hal ini sejalan dengan Hamdanillah et al. 2017) menyatakan bahwa penerapan model inkuiri dengan menggunakan video pembelajaran mampu meningkatkan hasil belajar peserta didik.

\section{PENUTUP}

Penerapan model inkuiri terbimbing dipadu advance organizer dalam pembelajaran fisika memberikan respon positif baik dari guru maupun peserta didik. Perangkat pembelajaran model inkuiri terbimbing dipadu advance organizer sangat baik diterapkan dalam proses pembelajaran fisika karena menumbuhkan motivasi, keaaktifan dan kerjasama peserta didik.

\section{UCAPAN TERIMAKASIH}

Tim peneliti mengucapkan terima kasih yang sebesar-besar kepada Kementerian Riset dan Pendidikan Tinggi yang telah membiayai penelitian ini melalui hibah penelitian tesis magister tahun 2019 .

\section{REFERENSI}

Ambarsari, W., Santosa, S., \& Mariadi. 2013. Penerapan Pembelajaran Inkuiri Terbimbing terhadap Keterampilan Proses Sains Dasar pada Pelajaran Biologi Siswa Kelas VIII SMP Negeri 7 Surakarta. Jurnal Pendidikan Biologi UNS, 5(1), 81-95.

Baity, N. \& Jatmiko, B. 2018. Senior High School Students Responses to Guided Inquiry Learning Model. Inovasi Pendidikan Fisika, 7(2), 208-210.

Dewi, S.M., Harjono, A., \& Gunawan. 2016. Pengaruh Model Pembelajaran Berbasis Masalah Berbantuan Simulasi Virtual Terhadap Penguasaan Konsep dan Kreativitas Fisika Siswa SMAN 2 Mataram. Jurnal Pendidikan Fisika dan Teknologi, 2(3), 123-128. 
Gunawan, G. 2015. Model Pembelajaran Sains berbasis ICT. FKIP Unram Press: Mataram.

Hamdanillah, N., Harjono, A., \& Susilawati. 2017. Pengaruh Model Pembelajaran Advance Organizer Menggunakan Video Pembelajaran terhadap Hasil Belajar Fisika Peserta Didik Kelas XI. Jurnal Pendidikan Fisika dan Teknologi, 3(2), 119-127.

Joyce, B., Weil, M., \& Calhoun, E. 2011. Models of Teaching (Model-Model Pengajaran). Jakarta: Pustaka Pelajar.

Kigo, J.K., Okere, M.I.O., Maghanga, C.M., \& Chemwei, B. 2018. Science Process Skills Advance Organizer and Students' Motivation Orientation in Secondary School Physics. Kabarak Journal of Reasearch Science Education, 6(1), 79-88.

Kusdiastuti, M., Harjono, A., Sahidu, H., \& Gunawan G. 2016. Pengaruh Model Pembelajaran Inkuiri Berbantuan Laboratorium Virtual Terhadap Penguasaan Konsep Fisika Peserta Didik. Jurnal Pendidikan Fisika dan Teknologi, 2(3), 116-122.

Nurmayani, L., Doyan, A., \& Verawati, N.N.S.P. 2018. Pengaruh Model Pembelajaran Inkuiri Terbimbing terhadap Kemampuan Berpikir Kritis. Jurnal Pendidikan Fisika dan Teknologi, 4(1), 98-104

Sanjaya, W. 2011. Strategi Pembelajaran Berorientasi Standar Proses Pendidikan. Jakarta: Kencana Prenada Media.

Tasiwan, Nugroho, S.E., \& Hartono. 2014. Pengaruh Advance Organizer Berbasis Proyek terhadap Kemampuan Analisis-Sintesis Siswa. Jurnal Pendidikan Fisika Indonesia, 10(1), 1-7.

Usmeldi, Amini, R., \& Trisna, S. 2017. The Development of Research-Based
Learning Model with Science, Environment, Technology, and Society Approaches to Improve Critical Thinking of Students. Jurnal Pendidikan IPA Indonesia, 6(2), 318-32.

Yeritia, S., Wahyudi, \& Rahayu, S. 2017. Pengaruh Model Pembelajaran Inkuiri Terbimbing terhadap Penguasaan Konsep dan Kemampuan Berpikir Kritis Fisika Peserta Didik Kelas X SMAN 1 Kuripan Tahun Ajaran 2017/2018. Jurnal Pendidikan Fisika dan Teknologi, 3(2), 181-187. 